\title{
Online Quiz as a formative assessment tool for undergraduate medical students in Medical Biochemistry
}

\author{
Das, $S$.
}

\section{Impact of COVID-19 on Teaching Learning}

A pandemic hit the world after a century and became the most unprecedented crisis of all times. The mainstay of controlling the Coronavirus (COVID-19) pandemic has been social distancing, contact tracing by the civic bodies around the world. Medical education had to redesign its pedagogy incorporating online learning into the curriculum. (Rose, 2020) Due to the limitation of in person training it has been difficult to continue the interactive sessions with students and conduct assessments online. Formative assessment essentially includes continuous feedback and correctives at each stage in the teachinglearning process. (Bennett, 2011) Formative assessment is most effective when it is nested in the ongoing teaching and learning program in order to facilitate timely, specific and actionable feedback to learners (Norcini et al., 2011). Formative assessment can be performed in many ways, including written tests or online quizzes. Students can regulate their own performance with the help of good formative assessments. We plan to conduct interactive online quiz and explore the educational value of formative assessment using online quiz for learning in biochemistry course.

\section{Proposed Session}

Telegram Chatbot Quiz (Telegram Messenger Inc, London, UK) feature is planned to be used to build a real time online quiz. A telegram group of 100 undergraduate students enrolled in our undergraduate program will be made. Twenty five questions will be formulated and the quiz will be conducted in real time. Before conducting the quiz, a preparatory session explaining the quiz structure and the use of Telegram app will be conducted via video conferencing. The Quiz will be followed by a group discussion which will be a feedback

Dr. Saswati Das

Atal Bahari Vajpayee Institute of Medical Sciences and Dr. Ram Manohar Lohia Hospital, New Delhi, India

Email:drsaswatidas@gmail.com session where the details of the answers asked in the Quiz will be discussed. For the feedback session 100 students will be divided into 4 groups, each comprising of 25 students. Each discussion will be conducted by a resident (post -graduate) using Zoom (Zoom Video Communications, Inc., San Jose, CA, USA). One faculty member will oversee the whole Quiz session. We also plan to explore the online Quiz session as an alternative tool for formative assessment.

\section{Why we chose Telegram}

The platform:

1. It is free;

2. It is user-friendly;

3. It has timer (real time);

4. It is compatible with smartphones, tablets and computers (desktop, laptop);

5. Widely used by students (already familiar)

\section{Possible Outcome}

To continue active learning has been a challenge during this pandemic. Conducting this Quiz session it is planned to evaluate the potential of online Quiz as a interactive teaching learning methodology and a tool for formative assessment. Challenges of internet connectivity for students in remote areas will have to be identified and addressed as the quiz will be conducted in real time.

\section{References}

Rose, S., 2020. Medical student education in the time of COVID-19. Jama.

Bennett, R.E., 2011. Formative assessment: A critical review. Assessment in education: principles, policy \& practice, 18(1), pp.5-25.

Norcini, J., Anderson, B., Bollela, V., Burch, V., Costa, M.J., Duvivier, R., Galbraith, R., Hays, R., Kent, A., Perrott, V. and Roberts, T., 2011. Criteria for good assessment: consensus statement and recommendations from the Ottawa 2010 Conference. Medical teacher, 33(3), pp.206-214.

DOI: http://doi.org/10.4038/seajme.v14i2.259 